\title{
El impacto de la crisis económica en las instituciones españolas y europeas
}

\author{
Miguel Sánchez Morón \\ Catedrático de Derecho Administrativo de la Universidad de Alcalá de Henares \\ miguel.sanchez@uah.es
}

Las ponencias que se han presentado en este seminario han expuesto ya, con profundidad y claridad, un análisis de la cuestión y muchas ideas sugerentes. Me limitaré a añadir una breve opinión no tanto nueva o distinta de las expresadas, sino más bien complementaria. Es solo una reflexión sobre las instituciones españolas y su reforma, no sobre las europeas.

Me parece necesario subrayar que el proceso de integración europea, que de hecho se ha acelerado con la crisis económica, y las sucesivas decisiones y acuerdos que se han adoptado en el ámbito europeo, incluyendo el MEDE y el Tratado de Estabilidad, Coordinación y Gobernanza, exigen en nuestro caso adoptar una serie de reformas estructurales de calado, también en el ámbito de las Administraciones Públicas. Esa exigencia ha quedado refrendada en el plano constitucional por la introducción de los principios de estabilidad presupuestaria y sostenibilidad financiera en el nuevo art. 135, que vienen a anclar (adicionalmente) nuestra Constitución a los principios en que se basa la Unión Económica y Monetaria. En relación con ello y de manera más amplia, podríamos decir que hoy en día la "Constitución económica", en sentido real, es la que se encuentra en los Tratados constitutivos de la Unión Europea, conforme a los cuales es necesario reinterpretar todas las cláusulas de nuestra propia Constitución, dada la primacía del Derecho europeo. Y esa Constitución económica europea se funda en la libertad económica y en el principio de concurrencia, que no es incompatible con los valores sociales, recogidos en el texto de los Tratados, ni tampoco con el mantenimiento de un sistema desarrollado de servicios públicos, siempre que éstos sean sostenibles económicamente.

Sin embargo, ni nuestra sociedad ni nuestra clase política han acabado de asumir o de asimilar esta nueva realidad "constitucional" - a diferencia de lo ocurrido en países del centro y del norte de Europa- y de ello se resiente el programa de reformas estructurales necesarias. Es lógico que los ciudadanos reaccionen frente a la supresión o recorte de los servicios y prestaciones que creíamos adquiridos para siempre y que muchos lo rechacen y protesten. Pero se debería haber explicado y haber entendido mejor que los servicios públicos del futuro serán sostenibles económicamente o no serán y que para eso habrá que generar los recursos suficientes -sobre todo por el sector privado-, habrá que ganar en eficiencia y eficacia administrativa y habrá que resolver los problemas institucionales que dificultan el recorte del déficit y de la deuda pública y el cumplimiento de las demás obligaciones que impone el Derecho europeo. Como eso no se ha asimilado socialmente, predomina la idea de que cualquier ajuste o rechazo es un nuevo atentado al tradicional "Estado del Bienestar", que seguimos creyendo eterno, lo que favorece la oposición frente a las reformas y la defensa a ultranza de los intereses corporativos en cada caso afectados.

A su vez, los partidos de uno y otro color y sus dirigentes - que cuando llegan al Gobierno no tienen más remedio que aplicar la política económica y las "recomendaciones" de Bruselas- lejos de hacer pedagogía de la nueva situación, procuran no enfrentarse a la marea de rechazo social (o lo hacen de manera tímida y autoexculpatoria) y, si están en la oposición, se sirven de ella y de los recortes inevitables para desgastar al adversario, sin entrar en un debate sincero. Eso sí, si las reformas les tocan de lleno, como por ejemplo las que implican reducir "el coste de la política", suele producirse una conjunción de intereses, para limitarlas a lo mínimo imprescindible o a lo aparente. El proceso de elaboración y el contenido final de la Ley de racionalización y sostenibilidad de la Administración Local es un buen ejemplo de lo que quiero decir.

Así las cosas, las reformas que son necesarias para adaptarse a la nueva situación -económica y constitu- 
cional- y que otros Estados han realizado ya, se abordan por así decir "a la defensiva" y o bien se quedan cortas -estrictamente lo que impone Bruselas y nada más- o bien no se aplican con rigor, una vez aprobadas (o ambas cosas). Puedo hacer referencia en este punto a las medidas del Informe CORA, bastante decepcionantes en algunos extremos, al criterio restrictivo y muchas veces meramente formal (o simulado) con que los distintos Gobiernos, de todo nivel y signo político, están procediendo a la "racionalización" del correspondiente sector público, o a la propia cortedad de la reforma de la Administración Local, que ni siquiera es claro que vaya a aplicarse en su integridad. De la reforma del sistema autonómico, por lo demás, ni hablamos.

En mi opinión, sería necesario dar pasos adelante en la comprensión y asunción colectiva de esa nueva situación, que es la del siglo que vivimos, y quienes tenemos algún tipo de responsabilidad intelectual deberíamos contribuir a ello. También a una nueva interpretación de nuestra Constitución conforme al nuevo contexto, es decir, a los principios de eso que Javier García Roca ha llamado aquí el "Derecho constitucional europeo", interpretación a la que parece orientarse alguna jurisprudencia reciente (por ejemplo en materia de distribución de competencias, que debe cohonestarse con la garantía de aplicación efectiva del Derecho europeo, o sobre el principio de estabilidad presupuestaria). La alternativa no sería la vuelta a un Estado del Bienestar como el que tuvimos (o soñamos), sino mantener ese racaneo reformador que resuelve poco y quizá nos aboque a nuevos períodos de inestabilidad. 